\title{
THE EFFECT OF CADMIUM ON THE COAGULATION AND FIBRINOLYTIC SYSTEM IN WOMEN WITH UTERINE ENDOMETRIAL CANCER AND MYOMA
}

\author{
MARZENNA NASIADEK ${ }^{1}$, ANNA KILANOWICZ ${ }^{1}$, ADAM DARAGO ${ }^{1}$, \\ ANDRZEJ LAZARENKOW ${ }^{2}$, and MARTA MICHALSKA ${ }^{3}$ \\ ${ }^{1}$ Medical University of Lodz, Łódź, Poland \\ Department of Toxicology, Faculty of Pharmacy \\ ${ }^{2}$ Medical University of Lodz, Łódź, Poland \\ Department of Bioinorganic Chemistry, Faculty of Pharmacy \\ ${ }^{3}$ Medical University of Lodz, Łódź, Poland \\ Department of Pharmaceutical Biochemistry, Faculty of Pharmacy
}

\begin{abstract}
Objectives: Cadmium (Cd) is a persistent and widespread environmental pollutant, which may constitute a potential risk factor for hormone-dependent tumors such as endometrial cancer. The vascular endothelium is an important target of cadmium toxicity, which may interfere with the coagulation cascade and fibrinolytic system. The aim of this research was to investigate whether in female patients with uterine endometrial cancer or myoma in comparison to healthy women, the concentration of cadmium in blood affects the process of coagulation and fibrinolysis. Materials and Methods: The study group comprised 91 women: 35 healthy (A-control), 39 with uterine myoma (B) and 17 with endometrial cancer (C), in which blood cadmium concentrations (BCd), coagulation and selected fibrinolysis parameters in plasma were assayed. Results: In the women with myoma and especially in those with endometrial cancer disturbances in coagulation and fibrinolysis were detected when compared to the healthy women. In the group of women with endometrial cancer significant changes in prothrombin index, levels of fibrinogen, fibrin D-dimer and t-PA were observed. Whereas, in the patients with myoma significant changes in prothrombin time, index of vWillebrand Factor and fibrin D-dimer level were noted. Mean BCd concentrations in subsequent groups were as follows: $\mathrm{B}-0.91 \pm 0.81 ; \mathrm{C}-0.78 \pm 0.45 \mu \mathrm{g} \mathrm{Cd} / \mathrm{l}$ and did not differ significantly in comparison with the control group $(0.86 \pm 0.35 \mu \mathrm{g} \mathrm{Cd} / \mathrm{l})$. However, in each study group smokers had approximately twice as high BCd as non-smokers. Studies also showed significant associations between BCd and fibrinogen level and thrombin time among the women with myoma and endometrial cancer, as well as in healthy women. Moreover, thrombin time significantly correlated with fibrinogen level in the women studied. Conclusions: In the patients with myoma and especially in these with endometrial cancer disturbances in coagulation and fibrinolysis parameters leading to hypercoagulability were detected. Exposure to cadmium can be one of the factors inducing these changes.
\end{abstract}

Key words:

Cadmium, Coagulation cascade, Endometrial cancer, Fibrinolysis, Myoma

This work was supported by Joint Project No 502-13-483 of the Medical University of Lodz, Poland: "Activity of fibrinolysis process in women with uterine myomas". Head of investigations: Marzenna Nasiadek, $\mathrm{PhD}$.

Received: August 8, 2012. Accepted: November 15, 2012.

Corresponding author: M. Nasiadek, Department of Toxicology, Faculty of Pharmacy, Medical University, Muszyńskiego 1, 90-151 Łódź, Poland (e-mail: marzenna.nasiadek@umed.lodz.pl). 


\section{INTRODUCTION}

Cadmium (Cd) belongs to heavy metals, and is very common both in the industry and in the natural environment. It is classified as the 7th substance on the Agency for Toxic Substances and Disease Registry Priority List of Hazardous Substances [1].

The main source of exposure to cadmium for general population is smoking tobacco or consumption of food containing cadmium [2-4]. Inhalation absorption is also efficient and thus smokers have 4-5 times greater blood cadmium levels than non-smokers [1,5]. Women are thought to be at greater risk of increased cadmium accumulation, as the concentrations of cadmium in blood and urine of females are significantly higher than in males due to the lower levels of iron [6]. Cd has a half-life of 3-4 months in blood and then it is transported to other parts of the body. It accumulates mainly in kidneys, liver and lungs [7]. In addition, as our earlier studies point out, it is also retained in reproductive organs [8]. Cadmium elimination from the organism is extremely slow and its biological half-life is $10-30$ years [9].

Due to the endocrine-disrupting properties of cadmium [10], it has been suggested that environmental exposure to it may cause estrogen-dependent diseases such as breast cancer and endometrial cancer [11-13].

Moreover, although uterine myomas belong to the group of hormone-dependent tumors, the participation of cadmium in their etiology has not been fully explained [1416]. Our earlier studies on women with myoma and endometrial cancer showed the accumulation of cadmium in the affected tissues. Moreover, a significant increase in calcium, as well as a decrease in iron concentration, was found in uterine cancer tissue [8]. These elements take part in blood coagulation process [17].

Furthermore, our research has confirmed that $\mathrm{Cd}$ concentration in blood significantly correlates with $\mathrm{Cd}$ level in uterine tissue in myoma and the surrounding myometrium. Moreover, in an additional path analysis a correlation between uterine tissue levels of $\mathrm{Cd}$ and $\mathrm{ER}$ (estrogen receptor) expression in women with myoma was identified [15]. In cancer patients, hyperviscosity may be a physiological link between "Traussean's syndrome" (carcinoma-induced coagulopathy), thrombosis and metastases [18,19]. Recent investigations have found that during tumor growth, angiogenesis and the coagulation cascade, the components of the fibrinolytic system are activated, and the function of the affected organs is impaired [20-22]. In addition, many authors suggest that smokers bear an increased risk of thromboembolic events, as well as vascular endothelium dysfunction [23-25]. However, not many data concerning the effect of cadmium on coagulation and fibrinolysis processes is available.

The aim of this research was to investigate whether in female patients with uterine endometrial cancer or myoma, in comparison to healthy women, the concentration of cadmium in blood affects the process of coagulation and fibrinolysis.

\section{MATERIALS AND METHODS}

\section{Study populations}

The control (group A) consisted of 35 healthy female volunteers, who performed routine gynecological check up in the health centre. The patients were classified to this group on the basis of the gynecological examination, ultrasonographic test, as well as morphological, coagulation and CRP assay (CRP $\leq 1 \mathrm{mg} / \mathrm{dl})$.

The study groups comprised 56 female patients with uterine tumor or cancer admitted to the Department of Gynecological Surgery, in Łódź over the years 2008-2009. On the basis of histopathological examination of tissues collected during the surgery, 56 patients were divided into two cohorts: group B comprising 39 patients with uterine myoma (intramural leiomyomas sine neoplasmate) and group $\mathrm{C}$ comprising 17 consecutive patients with uterine cancer (endometrial carcinoma Grade II and Grade III). Information concerning age, menopausal state, smoking 
history, the history of co-existing and past diseases, and the use of oral contraceptives was collected for the purpose of this study (groups A, B, C).

Self - reported cigarette smoking status was classified as: non-smoker ( $<100$ life time cigarettes) and current smoker ( $\leq 10$ pack-years; $>10$ pack-years). There were no former smokers in the group of the examined patients. "Pack-years of smoking" was calculated by multiplying the number of cigarette packets smoked per day by the number of years the person has smoked $(1$ pack-year $=20$ cigarettes per day for 1 year). In all the examined groups (A, B and $\mathrm{C}$ ) the proportion of current smokers was about $50 \%$. After an additional division of current smokers in the examined groups, in relation to pack-years, it was concluded that out of the three groups the group of patients with uterine myoma (group B) had the greatest number of smokers (> 10 pack-years).

The age of women in group A was between 30 and 57 years (mean: 47.32 \pm 5.79 ) and was not significantly different from the age of the patients with uterine myoma (group B - range: $31-55$ years; mean: $46.65 \pm 6.32$ ). However, the average age of the patients with endometrial cancer (group C) was significantly higher (50-79 years; mean: 67.43 \pm 9.85 ) in comparison with groups $\mathrm{A}$ and $\mathrm{B}$, due to the fact that this type of cancer is most frequently detected in women above 55 years during the pre- and post-menopausal periods. In groups $\mathrm{A}$ and $\mathrm{B}$, the number of subjects experiencing menopause was similar $(\mathrm{N}=5)$ and constituted approximately $15 \%$ of the total, whereas in group $\mathrm{C}(\mathrm{N}=7)$ it was about $50 \%$ of the whole group.

\section{Blood collection and tests}

Blood samples from the control (group A) were collected during routine tests, while blood samples of the women from groups $\mathrm{B}$ and $\mathrm{C}$ were collected before applying anticoagulant therapy with unfractionated heparin prior to the surgery. The samples were collected early in the morning by venipuncture in four separate types of vacutainers:
- an EDTA-anticoagulant prescreened for background metal contamination (S-Monovette, Sarsted, Germany), - without anticoagulant,

- with citrate (Becton Dickinson),

- with Li-heparin-anticoagulant for cadmium analysis (Monovette LH, Sarsted, Germany).

Plasma samples were prepared by centrifugation of blood at $2200 \times \mathrm{g}$ for $10 \mathrm{~min}$, and stored at $-20^{\circ} \mathrm{C}$. Prothrombin time (PT), thrombin time (TT), prothrombin index (PI), activated partial thromboplastin time (APTT), fibrinogen (F) concentration were measured by the use of an analyzer (Behring Coagulation System BCS XP, Dade Behring). Cadmium concentrations in whole blood were measured using graphite furnace atomic absorption spectrometry (GFAAS) at $228.8 \mathrm{~nm}$ (Hitachi Z-8270, Tokyo, Japan) with Zeeman correction. The limits of detection, calculated as the concentration corresponding to an absorption value equal to three times the standard deviation of the signal for the lowest standard, was $0.2 \mu \mathrm{g} / \mathrm{l}$. Seronorm Whole Blood-1 (Sero, Norway) was used as a reference material, containing cadmium at a concentration of $0.7 \mu \mathrm{g} / \mathrm{l}$. The relative standard deviation obtained in the reference material determinations was $5.65 \%$ for cadmium. Plasma levels of fibrin D-dimer (D-dimer Plus, Dade Behring), von Willebrand Factor (vWF) activity (BC, von Willebrand Reagent, Dade Behring) were measured by the use of a particle-enhanced immunoturbidimetric assay (BCS XP, Dade Behring).

Tests ELISA were used to measure plasminogen activator inhibitor-1 (PAI-1) (Zymutest PAI-1 antigen, Hyphen Biomed), tissue plasminogen activator (t-PA) (Elitest t-PA antigen, Hyphen Biomed), PAP complex (Technoclone TC) and concentration of Factor VII antigen (Asserachrom VII:Ag, Diagnostica Stago). The plasma activity of antithrombin III (AT III) was estimated by the use of chromogenic substrate (Berichrom AT III, BCS XP, Dade Behring). All the assays of the above mentioned parameters were performed within 1 week after collection of the blood samples. 


\section{Ethical approval}

The study design was approved by the Ethics Committee for Scientific Research of Medical University of Lodz (No. RNN/156/02/KE). All female patients participating in the experiments gave their explicit consent to the study.

\section{Statistical analyses}

The obtained data was analyzed using StatSoft STATISTICA 9.0 PL. The Mann-Whitney test was used to compare the data obtained in two independent groups (B and $\mathrm{C}$ ) with the data from the control group (A). The level of statistical significance was established at the value of $p \leq 0.05$. Spearman's rank correlation test was applied to assess univariate associations.

\section{RESULTS}

\section{Cadmium concentrations in blood}

In all patients, the cadmium body burden was assessed by measuring its concentration in blood, which is regarded as an important indicator of recent exposure to cadmium [26]. The mean blood Cd concentration (BCd) was not found to be significantly different between the groups of patients (A: $0.86 \pm 0.35 \mu \mathrm{g} \mathrm{Cd/l;} \mathrm{B:} 0.91 \pm 0.81 \mu \mathrm{g} \mathrm{Cd} / \mathrm{l}$; C: $0.78 \pm 0.45 \mu \mathrm{g} \mathrm{Cd} / \mathrm{l})$ (Table 1).

After dividing the patients into current smokers and non smokers in each examined group (A, B, C), the concentration of $\mathrm{BCd}$ among non-smokers did not significantly differ between the groups. The BCd levels of the current smokers (groups A, B, C) were approximately twice as high as those of the non smokers, irrespective of the pack-year value. Nevertheless, no statistically significant differences were detected between the groups A, B and C in current smokers (Table 1).

\section{Blood and fibrinolysis parameters}

In Table 2, changes in coagulation and fibrinolysis parameters in each study group are presented. The most significant changes in the studied parameters were observed in the women with endometrial cancer $(\mathrm{C})$ in comparison with the control. In this group $(\mathrm{C})$ the level of fibrinogen (acute phase proteins) was significantly higher than in the control group (A) and group B. Moreover, in group C, a decrease in the levels of prothrombin index were observed, whereas fibrin D-dimer levels were approximately two-fold higher, and t-PA levels about 30\% higher in comparison to the control group (Table 2).

Table 1. Blood cadmium concentration (BCd) in the women as dependent on smoking status

\begin{tabular}{lcccccc}
\hline \multirow{2}{*}{ Variables } & $\begin{array}{c}\text { Controls } \\
\text { (group A) }\end{array}$ & $\begin{array}{c}\text { Women with uterine myoma } \\
\text { (group B) }\end{array}$ & $\begin{array}{c}\text { Women with endometrial cancer } \\
\text { (group C) }\end{array}$ \\
\cline { 2 - 7 } & $\mathrm{n}$ & $\begin{array}{c}\mathrm{BCd}(\mu \mathrm{g} / \mathrm{l}) \\
\mathrm{M} \pm \mathrm{SD}\end{array}$ & $\mathrm{n}$ & $\begin{array}{c}\mathrm{BCd}(\mu \mathrm{g} / \mathrm{l}) \\
\mathrm{M} \pm \mathrm{SD}\end{array}$ & $\mathrm{n}$ & $\begin{array}{c}\mathrm{BCd}(\mu \mathrm{g} / \mathrm{l}) \\
\mathrm{M} \pm \mathrm{SD}\end{array}$ \\
\hline $\begin{array}{l}\text { All patients in the group } \\
\text { Smoking status }\end{array}$ & 35 & $0.86 \pm 0.35$ & 39 & $0.91 \pm 0.81$ & 17 & $0.78 \pm 0.45$ \\
$\quad$ non-smokers & 19 & $0.44 \pm 0.25$ & 23 & $0.65 \pm 0.48$ & 11 & $0.56 \pm 0.27$ \\
$\quad$ current smokers (pack-years) & 16 & $1.09^{*} \pm 0.32$ & 16 & $1.72^{*} \pm 0.94$ & 6 & $1.30^{*} \pm 0.58$ \\
$\quad \leq 10$ & 9 & $0.96^{*} \pm 0.20$ & 6 & $1.79^{*} \pm 1.22$ & 3 & $1.00^{*} \pm 0.21$ \\
$>10$ & 7 & $1.25^{* *} \pm 0.39$ & 10 & $1.66^{* *} \pm 0.36$ & 3 & $1.37^{* *} \pm 0.48$ \\
\hline
\end{tabular}

$\mathrm{n}$ - numbers of objects are expressed as absolute values.

$\mathrm{M}$ - mean, SD - standard deviation.

$* \mathrm{p} \leq 0.05$ vs. non-smokers.

$* * \mathrm{p} \leq 0.01$ vs. non-smokers. 
Table 2. Hemostatic parameters in healthy women (controls), patients with uterine myoma and patients with endometrial cancer

\begin{tabular}{lccc}
\hline \multicolumn{1}{c}{ Parameters } & Controls & Women with uterine myoma & Women with endometrial cancer \\
& $\mathrm{M} \pm \mathrm{SD}$ & $\mathrm{M} \pm \mathrm{SD}$ & $\mathrm{M} \pm \mathrm{SD}$ \\
\hline APTT (s) & $30.89 \pm 3.11$ & $30.26 \pm 2.92$ & $30.47 \pm 3.89$ \\
PT (s) & $11.73 \pm 0.60^{* \mathrm{~B}}$ & $12.35 \pm 1.18^{* \mathrm{~A}}$ & $12.04 \pm 1.18$ \\
TT (s) & $18.29 \pm 0.98$ & $18.25 \pm 1.33$ & $17.76 \pm 1.20$ \\
P Index (\%) & $102.39 \pm 5.07^{* \mathrm{C}, * * \mathrm{~B}}$ & $93.06 \pm 9.42^{* * \mathrm{~A}}$ & $96.25 \pm 10.15^{* \mathrm{~A}}$ \\
Fibrinogen (g/l) & $3.93 \pm 0.67$ & $3.50 \pm 0.84$ & $4.60 \pm 0.71^{* \mathrm{~A}, * * \mathrm{~B}}$ \\
D-dimer (ng/ml) & $80.81 \pm 40.10^{* \mathrm{~B}, * * \mathrm{C}}$ & $175.92 \pm 72.40^{* \mathrm{~A}}$ & $182.20 \pm 77.60^{* * \mathrm{~A}}$ \\
vWF (\% Atv) & $124.14 \pm 41.60^{* \mathrm{~B}}$ & $86.70 \pm 47.70^{* \mathrm{~A}, \mathrm{C}}$ & $155.65 \pm 45.10^{* \mathrm{~B}}$ \\
Factor VII antigen $(\%)$ & $97.48 \pm 18.80$ & $126.08 \pm 63.60$ & $113.04 \pm 30.60$ \\
AT III (\% Atv) & $99.65 \pm 10.90$ & $93.63 \pm 13.30$ & $102.01 \pm 9.20$ \\
PAP (ng/ml) & $300.91 \pm 128$ & $323.35 \pm 216.00$ & $246.86 \pm 122.00$ \\
t-PA (ng/ml) & $5.98 \pm 1.82^{* * \mathrm{C}}$ & $5.65 \pm 2.04 * \mathrm{C}$ & $7.70 \pm 2.38^{* * \mathrm{~A}, \mathrm{~B}}$ \\
PAI-1 (ng/ml) & $11.95 \pm 4.57$ & $13.52 \pm 9.16$ & $16.61 \pm 7.01$ \\
\hline
\end{tabular}

$\mathrm{M}$ - mean, SD - standard deviation.

Atv - activity.

* Statistical difference $(\mathrm{p} \leq 0.05)$ from the patients groups (A or B or C).

** Statistical difference $(\mathrm{p} \leq 0.01)$ from the patients groups (A or B or C).

A - control healthy women (group A).

$\mathrm{B}$ - women with uterine myomas (group B).

$\mathrm{C}$ - women with endometrial cancer (group C).

On the other hand, in the patients with myoma, the changes in coagulation were smaller but statistically significant in comparison to the control females. The decrease in prothrombin index level was comparable to the one in the group of patients with endometrial cancer, whereas an increase was detected in vWF activity. Additionally, no significant changes in the mean level of fibrinogen among the women with myoma were observed, contrary to the patients with endometrial cancer. The changes in fibrinolytic parameters (D-dimer) in the group with myoma were smaller than the ones detected in the patients with endometrial cancer. In group B (myoma), no increase of t-PA level was observed.

No significant differences in medium plasma levels of APTT, TT, PAP, PAI-1 and in the activity of Factor VII, AT III were detected between groups A, B and $\mathrm{C}$.
In order to investigate the effect of $\mathrm{Cd}$ on the process of coagulation and fibrinolysis, the Spearman's correlation coefficients between $\mathrm{Cd}$ concentration in blood and the estimated parameters were calculated (Table 3). A significant, negative correlations between $\mathrm{BCd}$ and thrombin time were noted in both control group ( $\mathrm{rs}=-0.34$ ) and in the women with endometrial cancer ( $\mathrm{rs}=-0.38$ ), also an insignificant correlation was observed in the patients with myoma ( $r s=-0.28$ ). Furthermore, BCd was positively associated with the level of fibrinogen in all of the examined patients: in the control group ( $\mathrm{rs}=0.45$ ), in the myoma group ( $\mathrm{rs}=0.40)$ and in the endometrial cancer group ( $r s=0.32$ ). In addition, significant negative associations between thrombin time and fibrinogen level were stated in all three groups. Also, prothrombin index was correlated with Factor VII antigen in groups B and C ( $\mathrm{rs}=-0.41$; rs $=-0.61$, respectively. 
Table 3. Associations between hemostatic parameters and the blood cadmium concentration (Sperman's rank correlation coefficient) in the investigated women

\begin{tabular}{|c|c|c|c|c|c|c|}
\hline Parametrs & Groups & $\begin{array}{l}\text { TT } \\
\text { (s) }\end{array}$ & $\begin{array}{c}\mathrm{F} \\
(\mathrm{g} / \mathrm{l})\end{array}$ & $\begin{array}{c}\text { Factor VII } \\
\text { antigen } \\
(\%)\end{array}$ & $\begin{array}{c}\mathrm{t}-\mathrm{PA} \\
(\mathrm{ng} / \mathrm{ml})\end{array}$ & $\begin{array}{c}\text { PAI-1 } \\
(\mathrm{ng} / \mathrm{ml})\end{array}$ \\
\hline \multirow[t]{3}{*}{$\mathrm{BCd}(\mu \mathrm{g} / \mathrm{l})$} & A & $-0.34^{*}$ & $0.45^{* *}$ & & & \\
\hline & B & -0.28 & $0.40^{*}$ & & & \\
\hline & $\mathrm{C}$ & $-0.38^{*}$ & $0.32 *$ & & & \\
\hline \multirow[t]{3}{*}{ TT (s) } & A & & $-0.50^{* *}$ & & & \\
\hline & B & & $-0.53^{* *}$ & & & \\
\hline & $\mathrm{C}$ & & $-0.48^{*}$ & & & \\
\hline \multirow[t]{3}{*}{ P Index (\%) } & A & & & -0.08 & & \\
\hline & B & & & $-0.41^{*}$ & & \\
\hline & $\mathrm{C}$ & & & $-0.61^{*}$ & & \\
\hline \multirow[t]{3}{*}{$\mathrm{F}(\mathrm{g} / \mathrm{l})$} & A & & & & -0.08 & \\
\hline & B & & & & $0.51^{*}$ & \\
\hline & $\mathrm{C}$ & & & & -0.15 & \\
\hline \multirow[t]{3}{*}{ vWF (\%Atv) } & A & & & & 0.09 & 0.05 \\
\hline & B & & & & 0.30 & 0.10 \\
\hline & $\mathrm{C}$ & & & & $0.58^{*}$ & $0.68^{* *}$ \\
\hline \multirow[t]{3}{*}{ D-dimer (ng/ml) } & A & & 0.32 & & & \\
\hline & B & & 0.03 & & & \\
\hline & $\mathrm{C}$ & & $0.42 *$ & & & \\
\hline \multirow[t]{3}{*}{ t-PA (ng/ml) } & A & & & & & 0.24 \\
\hline & B & & & & & 0.08 \\
\hline & $\mathrm{C}$ & & & & & $0.63^{*}$ \\
\hline
\end{tabular}

$* p \leq 0.05$.

$* * \mathrm{p} \leq 0.01$.

A - control healthy women (group A).

B - women with uterine myomas (group B).

$\mathrm{C}$ - women with endometrial cancer (group C).

The fibrin D-dimer level was only found to be significantly dependent on the level of fibrinogen in plasma in the endometrial cancer group ( $\mathrm{rs}=0.42$ ). However, no correlation between the level of fibrin $\mathrm{D}$-dimer and the concentration of $\mathrm{BCd}$ was observed. Also, only in this group (C) vWF (\% activity) was correlated with t-PA level ( $\mathrm{rs}=0.58)$ and PAI-1 level ( $\mathrm{rs}=0.68$ ), as well as t-PA level correlated with PAI-1 level ( $\mathrm{rs}=0.63$ ).

In group B (myoma) the level of fibrinogen significantly correlated with the level of t-PA ( $r s=0.51$ ), and did not depend on the level of fibrin D-dimer. No other significant correlations were detected between the remaining assayed coagulation and fibrinolysis parameters.

\section{DISCUSSION}

In the presented study, significant changes were exemplified in coagulation parameters and fibrinolysis, both in the women with endometrial cancer and in the group of patients with myoma in comparison with the healthy 
women. In the women with myoma the changes were less pronounced. Statistical analysis showed the correlations between cadmium concentration in blood and the level of fibrinogen and shortening of the thrombin time in the plasma of all the examined and control women. This may suggest that cadmium exerts toxic effect on the vascular endothelium leading to hypercoagulability.

However, it has been observed that coagulation factors and regulatory proteins are upregulated in the patients with gastric cancer [27], colorectal cancer [28], gynecological cancer [29], and cervical cancer [30]. However, there are no studies on women with myoma, except for some data in literature from the 1960s [31]. In our study in the patients with myoma, in comparision to the control group, prolongation of prothrombin time, a decrease in prothrombin index and vWF (\% activity) and an increase in fibrin D-dimer level were observed, in comparison to the control group. The most pronounced disturbances in the process of coagulation and fibrinolysis in blood plasma were observed in the group of patients with endometrial cancer, which is confirmed by the results obtained by other authors [32]. We observed an increase in fibrinogen plasma level with a simultaneous decrease in prothrombin index, and an increase in fibrin D-dimer and t-PA levels. The aim of this research was to investigate whether in female patients with uterine endometrial cancer or myoma, in comparison to healthy women, the concentration of cadmium in the blood affects the process of coagulation and fibrinolysis.

In our study, mean concentration of cadmium in blood of women (including non-smokers and current smokers) did not differ significantly among the groups (A, B, C). Similar results were obtained by Jackson et al. [16]. The major source of cadmium in general population is cigarette smoke (both active and passive) and food. In this study we observed approximately a two-fold increase in the level of cadmium in blood of the smokers in all the examined groups over the non-smokers. However, the mean $\mathrm{BCd}$ concentration in the non-smokers was similar to the reference value $(0.8 \mu \mathrm{g} / \mathrm{l})$ [5]. It is generally known that smoking exerts a considerable effect on the level of $\mathrm{Cd}$ in blood. It has been estimated that a person smoking 20 cigarettes a day absorbs about $1 \mu \mathrm{g} \mathrm{Cd/day} \mathrm{[33].}$

Furthermore, as in previous studies, cadmium accumulation was confirmed in the myometrium, as well as in the tissues of the patients with myoma and those with endometrial cancer. The levels of cadmium accumulated in the myometrium surrounding the neoplastic tissue were higher than in the neoplastic tissue itself, which probably results from the fact that these are fast growing tissues. In our earlier studies, statistical analysis also demonstrated a significant correlation between $\mathrm{BCd}$ concentration and $\mathrm{Cd}$ level in uterine tissues [8,15].

Apart from the effect on internal organs, cadmium may also destroy the vascular endothelium, one of the primary targets of $\mathrm{Cd}$ toxicity [34,35]. It has been suggested that the effect of $\mathrm{Cd}$ on the vascular endothelium results in a loss of barrier integrity, and an increase in endothelial permeability which, could result in edema, hemorrhage, hypoxia, inflammation and changes in the coagulation cascade and fibrinolysis [36].

In this study in all the examined women the Sperman's correlation analysis showed that elevated BCd concentrations were correlated with the increased fibrinogen plasma levels. The presented correlation between BCd and fibrinogen level confirms the study of Lin et al. [37], which demonstrated a similar correlation between $\mathrm{Cd}$ concentration in urine and fibrinogen plasma levels in cohort research on humans. It has been suggested that the increase in the plasma fibrinogen level may result from the effect of the associated cadmium exposure on the vascular endothelial cells, which are the initial site of hepatic injury especially in smoking female patients, which was confirmed by studies performed on animals [38].

Fibrinogen is an acute phase protein and a dimeric glycoprotein as well as the plasma component, which is 
synthesized exclusively in the liver [39]. It plays a crucial role in the final stage of the coagulation cascade and in the process of platelet aggregation. Elevated fibrinogen plasma levels can cause among others: hypercoagulability and hypoxia, which may lead to growing tumors, by the production of tumor cells themselves, or by inflammation-mediating cells such as epithelial cells, as a tumor response [40-42]. Polterauer et al. [30] also suggest that fibrinogen level is an independent prognostic parameter in the patients with cervical cancer.

We have also shown a significant, negative correlations between BCd and thrombin time in both, the control group (rs $=-0.34$ ) and in the women with endometrial cancer ( $\mathrm{rs}=-0.38$ ), whereas insignificant correlation was observed in the patients with myoma ( $\mathrm{rs}=-0.28$ ).

Thrombin time shows the speed at which fibrinogen is converted into fibrin under the influence of the specific serine protease - thrombin. Its shortening may suggest hypercoagulability caused by increased fibrinogen level, as well as increased activity of the factors within the intrinsic and extrinsic coagulation system. Thus, the obtained correlation between thrombin time and BCd concentration suggests intense production of fibrin, which, being an angiogenic factor, may lead to tumor growth [43]. Along with the shortened thrombin time and increased speed of fibrin production, we observed an increase in vWF activity, which is responsible for aggregation and platelet adhesion, and creating a fibrin in the patients with endometrial cancer. Experiments performed on rats after exposing the animals to $15 \mathrm{ppm} \mathrm{CdCl}_{2}$ (per os) demonstrated shortening of prothrombin time and activated partial thromboplastin time and antithrombin activities, which can lead to hypercoagulability [44]. However, the concentrations of cadmium in the blood of rats quoted by other authors are very high, and seem to be improbable, taking literature data into consideration.

The intensified activity of the fibrinolytic system determines the formation of the D-dimer as fibrin degradation product. The D-dimer is a very useful homeostatic parameter that can gauge ongoing fibrin formation and degradation in some diseases, including ovarian cancer $[29,45]$. In our research, like in von Tempelhoff et al. study [19] we have shown a two-fold increase of fibrin D-dimer plasma level, which correlated with fibrinogen level, in the women with endometrial cancer as compared to the control group. Increased fibrin D-dimer plasma levels in the females with myoma, seem to be important as well, although there was no correlation between the level of fibrin D-dimer and fibrinogen level.

Despite lack of correlation between $\mathrm{BCd}$ and fibrin D-dimer level, it cannot be excluded that fibrinolysis-induced endothelial damage may be disturbed by cadmium. It is suggested that the mechanism of fibrinolytic system activation by cadmium may result from multidirectional effect of this metal, including interactions with essential elements, disturbances of red-ox processes or increased endothelium permeability [46,47].

In plasma of the women with endometrial cancer, an increase of t-PA level was detected, which did not occur in the women with myoma. The t-PA is a serine protease, synthesized mostly by endothelial cells and apart from u-PA (urokinase plasminogen activator) acts as a plasmin activator. PAI-1 and PAI-2 act as primary inhibitors of these proteins. Research conducted by Yamamoto and Kaji [48] indicates that cadmium reduces the activity of both $\mathrm{t}$-PA and u-PA in vascular endothelial cells through induction of PAI-1 synthesis, which is mediated by protein kinase $\mathrm{C}$ activation. However, in our study, increases in PAI-1 concentration were only observed in the groups of females with endometrial cancer. The level of PAI-1 depends, among other factors, on estradiol concentration, hence it is impossible to exclude the fact that cadmium, by influencing the endocrine system, may act as an element increasing the level of PAI-1 [49].

Furthermore, elevated levels of markers of fibrinolysis have been reported in the healthy smokers. In vivo studies [50] have demonstrated major impairment of t-PA release from 
the vascular endothelium of smokers. The primary inhibitor of fibrinolysis is PAI-1, which inhibits plasminogen activation by binding with t-PA to the PAI/t-PA complexes. Current smoking is associated with a significant increase in t-PA antigen, which represents mainly the circulating PAI/t-PA complexes and indicates impaired fibrinolytic activity in smokers [51]. Thus, we cannot exclude the fact that the confounding factor is the exposure to tobacco smoke, which is closely correlated with the blood cadmium concentration.

\section{CONCLUSIONS}

In the conducted studies in the women with endometrial cancer and myoma, especially in the group of patients with endometrial cancer, disturbances in coagulation and fibrinolysis were detected in comparison with the healthy women. The exemplified correlations between cadmium concentration in blood and the level of fibrionogen, as well as shortened thrombin time, suggest that cadmium may act as one of the factors leading to hypercoagulability.

The effects of cadmium on coagulation and fibrinolysis deserve further study in larger and more representative populations.

\section{RFERENCES}

1. Agency for Toxic Substances and Disease Registry. Toxicological Profile for Cadmium. US Department of Health and Human Service. Atlanta, GA: ATSDR; 2011. [cited 2012 Jul 29]. Available from URL: http://www.atsdr.cdc.gov.

2. Jarup L, Akesson A. Current status of cadmium as an environmental health problem. Toxicol Appl Pharmacol 2009;238: 201-8. DOI: 10.1016/j.taap.2009.04.020.

3. McElroy JA, Shafer MM, Trentham-Dietz A, Hampton JM, Newcomb PA. Urinary cadmium levels and tobacco smoke exposure in women age 20-69 years in the United States. J Toxicol Environ Health A 2007;70:1779-82. DOI: $10.1080 / 15287390600754953$.
4. Richter PA, Bishop EE, Wang J, Swahn MH. Tobacco smoke exposure and levels of urinary metals in the U.S. youth and adult population: the National Health and Nutrition Examination Survey (NHANES) 1999-2004. Int J Environ Res Public Health 2009;6(7):1930-46. DOI: 10.3390/ijerph6071930.

5. Wilhelm M, Ewers U, Schulz C. Revised and new reference values for some trace elements in blood and urine for human biomonitoring in environmental medicine. Int J Hyg Environ Health 2004;207:69-73.

6. Vahter M, Berglund M, Akesson A, Liden C. Metals and women's health. Environ Res Sec A 2002;88:145-55. DOI: 10.1006/enrs.2002.4338.

7. Elinder CG, Kjellstrom T. Carcinogenic and mutagenic effects. In: Friberg L, Elinder CG, Kjellstrom T, Nordberg GF, editors. Cadmium and health: A toxicological and epidemiological appraisal. Boca Raton: CRC Press; 1986. p. 205-29.

8. Nasiadek M, Krawczyk T, Sapota A. Tissue levels of cadmium and trace elements in patients with myoma and uterine cancer. Hum Exp Toxicol 2005;24:623-30. DOI: 10.1191/0960327105ht575oa.

9. Jarup L, Berglund M, Elinder CG, Nordberg G, Vahter M. Health effects of cadmium exposure - A review of the literature and a risk estimate. Scan J Work Environ Health 1998;24(1): $1-51$.

10. Stoica A, Katzenellenbogen BS, Martin MB. Activation of estrogen receptor- $\alpha$ by the heavy metal cadmium. Mol Endocrinol 2000;14(4):545-53. DOI: 10.1210/me.14.4.545.

11. Akesson A, Julin B, Wolk A. Long-term dietary cadmium intake and postmenopausal endometrial cancer incidence: A population-based prospective cohort study. Cancer Res 2008;68:6435-41. DOI: 10.1158/0008-5472.CAN-080329.

12. McElroy JA, Shafer MM, Trentham-Dietz A, Hampton JM, Newcomb PA. Cadmium exposure and breast cancer risk. J Natl Cancer Inst 2006;98(12):869-73. DOI: 10.1093/jnci/ djj233.

13. Nawrot T, Plusquin M, Hogervorst J, Roels HA, Celis H, Thijs L, et al. Environmental exposure to cadmium and risk 
of cancer: A prospective population-based study. Lancet Oncol 2006;7:119-26. DOI: 10.1016/S1470-2045(06)70545-9.

14. Heilier J-F, Verougstraete V, Nackers F, Tonglet R, Donnez J, Lison D. Assessment of cadmium impregnation in women suffering from endometriosis: A preliminary study. Toxicol Lett 2004;154:89-93. DOI: 10.1016/j.toxlet2004.07.006.

15. Nasiadek M, Swiatkowska E, Nowinska E, Krawczyk T, Wilczynski JR, Sapota A. The effect of cadmium on steroid hormones and their receptors in women with uterine myomas. Arch Environ Contam Toxicol 2011;60:734-41. DOI: 10.1007/s00244-010-9580-8. Erratum in: Arch Environ Contam Toxicol 2012;62:359. DOI: 10.1007/s00244-011-9694-7.

16. Jackson LW, Zullo MD, Goldberg JM. The association between heavy metals, endometriosis and uterine myomas among premenopausal women: National Health and Nutrition Examination Survey 1999-2002. Human Reprod 2008;23(3): 679-87. DOI: 10.1093/humrep/dem394.

17. Metz W. Trace minerals and atherosclerosis. Fed Proc 1982;41(11):2807-12.

18. Goldenberg N, Kahn SR, Solymoss S. Markers of coagulation and angiogenesis in cancer-associated venous thromboembolism. J Clin Oncol 2003;21:4194-99. DOI: 10.1200/ JCO.2003.05.165.

19. Von Tempelhoff G-F, Schönmann N, Heilmann L, Pollow K, Hommel G. Prognostic role of plasma viscosity in breast cancer. Clin Hem Microcirc 2002;26:55-61.

20. Piccioli A, Prandoni P. Screening for occult cancer in patients with idiopathic venous thromboembolism: Yes. J Thromb Haemost 2003;1(11):2271-2. DOI: $\quad$ 10.1046/j.15387836.2003.00505.x.

21. Sallah S, Wan JY, Nguyen NP, Hanrahan LR, Sigounas G. Disseminated intravascular coagulation in solid tumors: clinical and pathologic study. Thromb Haemost 2001;86(3): 828-33.

22. Kvolik S, Jukic M, Matijevic M, Marianovic K, GlavasObrovac L. An overview of coagulation disorders in cancer patients. Surg Oncol 2010;19:e33-46. DOI: 10.1016/j.suronc.2009.03.008.
23. Satarug S, Moore MR. Adverse health effects of chronic exposure to low-level cadmium in foodstuffs and cigarette smoke. Environ Health Perspect 2004;112:1099-103. DOI: 10.1289/ ehp.6751.

24. Navas-Acien A, Silbergeld EK, Sharrett R, Calderon-Aranda E, Selvin E, Guallar E. Metals in urine and peripheral arterial disease. Environ Health Perspect 2005;113:164-9. DOI: 10.1289/ehp.7329.

25. Tellez-Plaza M, Navas-Acien A, Crainiceanu CM, Sharrett AR, Guallar E. Cadmium and peripheral arterial disease: gender differences in the 1999-2004 US National Health and Nutrition Examination Survey. Am J Epidemiol 2010;15;172(6):671-81. DOI: 10.1093/aje/kwq172.

26. Buchet JP, Lauwerys R, Roels H, Bernard A, Bruaux P, Claeys F, et al. Renal effects of cadmium body burden of the general population. Lancet 1990;22:336(8717):699-702. Erratum in: Lancet 1991;22:337(8756):1554. DOI: 10.1016/01406736(90)92201-R.

27. Yamashita H, Kitayama J, Kanno N, Yatomi Y, Nagawa $\mathrm{H}$. Hyperfibrinogenemia is assocciated with lymphatic as well as hematogenous metastasis and worse clinical outcome in T2 gastric cancer. BMC Cancer 2006;6:147-155. DOI: 10.1186/1471-2407-6-147.

28. Wang Q, Xie R, Zang QY. Clinical significance of plasma fibrinogen level in patients with colorectal cancer. Zhong Zhong Liu Za Zhi 2005;27:544-6.

29. Wang X, Fu S, Freedman RS, Kavanagh JJ. Venous thromboembolism syndrome in gynecological cancer. Int J Gynecol Cancer 2006;16 Suppl:458-71.

30. Polterauer S, Seebacher V, Hefler-Frischmuth K, Grimm C, Heinze G, Tempfer C, et al. Fibrinogen plasma levels are an independent prognostic parameter in patients with cervical cancer. Am J Obstet Gynecol 2009;200:647e1-7. DOI: 10.1016/ j.ajog2009.01.008.

31. Roszkowski I, Czerwińska JJ, Niewiarowska MM, Bar-Pratkowska JJ. The plasma clotting system in women with myomas of the uterus. Ginecol Pol 1969;40(8):911-5 [in Polish]. 
32. Von Tempelhoff GH, Nieman F, Heilmann L, Homnel G. Association between blood rheology, thrombosis and cancer survival in patients with gynecologic malignance. Clin Hemorheol Microcirc 2000;22:107-30.

33. Satarug S, Baker JR, Urbenjapol S, Haswell-Elkins M, Reilly PEB, Williams DJ, et al. A global perspective on cadmium pollution and toxicity in non-occupationally exposed population. Toxicol Lett 2003;137:65-83. DOI: 10.1016/S03784214(02)00381-8.

34. Kishimoto T, Fukuzawa Y, Abe M, Isobe M, Hashimoto M, Tada M. Cadmium injury of cultured human vascular endothelial cells. Human Cells 1991;4(4):329-34.

35. Kaji T, Mishima A, Yamamoto C, Sakamoto M, Koizumi F. Effect of cadmium on the monolayer maintenance of vascular endothelial cells in culture. Toxicology 1992;71:267-76.

36. Prozialeck WC, Edwards JR, Woods JM. The vascular endothelium as a target of cadmium toxicity. Life Sci 2006;79:1493-506. DOI: 10.1016/j.lfs2006.05.007.

37. Lin Y-S, Rathod D, Ho W-C, Caffrey JJ. Cadmium exposure is associated with elevated blood C-reactive protein and fibrinogen in the U.S. Population: The Third National Health and Nutrition Examination Survey (NHANES III, 1988-1994). Ann Epidemiol 2009;19(8):592-6. DOI: 10.1016/j.annepidem.2009.02.005.

38. Kuester RK, Waalkes MP, Goering PL, Fisher BL, McCuskey RS, Sipes IG. Differential hepatotoxicity induced by cadmium in Fischer 344 and Sprague-Dawley rats. Toxicol Sci 2002;65(1):151-9. DOI: 10.1093/toxsci/65.1.151.

39. Chandler WL, Rodgers GM, Sprouse JT, Thompson AR. Elevated hemostatic factor levels as potential risk factors for thrombosis. Arch Pathol Med 2002;126:1405-14.

40. Falanga A, Rickles FR. Pathophysiology of the thrombophilic state in the cancer patients. Semin Thromb Hemost 1999;25:173-82. DOI: 10.1055/s-2007-994919.

41. Palumbo JS, Kombrinck KW, Drew AF, Grimes TS, Kiser JH, Degen JL, et al. Fibrinogen is an important determinant of the metastatic potential of circulating tumor cells. Blood 2000;96:3302-9.
42. Gouin-Thibault I, Achkar A, Samama MM. The thrombophilic state in cancer patients. Acta Haematol 2001;106:33-42. 43. Sahni A, Simpson-Haidaris PJ, Sahni SK, Vaday GG, Francis CW. Fibrinogen synthesized by cancer cells augments the proliferative effect of fibroblast growth factor-2 (FGF-2). J Thromb Haemost 2008;6(1):176-83. DOI: 10.1111/j.15387836.2007.02808.x.

44. Kocak M, Akcil E. The effects of chronic cadmium toxicity on hemostatic system. Pathophysiol Haemost Throm 2006;35:411-6. DOI: 10.1159/000102047.

45. Kodama J, Seki N, Masahiro S, Kusumoto T, Nakamura K, Hongo A, et al. D-dimer level as a risk factor for postoperative venous thromboembolism in Japanese women with gynecologic cancer. Ann Oncol 2010;21:1651-6. DOI: 10.1093/annonc/mdq012.

46. Nordberg GF, Nogawa K, Nordberg M, Friberg L. Cadmium . In: Nordberg GF, Fowler BA, Nordberg M, Friberg L, editors. Handbook on the Toxicology of metals. 3rd ed. USA: Academic Press, San Diego; 2007. p. 445-86.

47. Wolf MB, Baynes JW. Cadmium and mercury cause an oxidative stress induced endothelial dysfunction. Biometals 2007;20:73-81. DOI: 10.1007/s10534-006-9016-0.

48. Yamamoto C, Kaji T. Induction of plasminogen activator inhibitor type 1 synthesis by cadmium in human vascular endothelial cells in culture. J Health Sci 2002;48(1):55-61.

49. Van Kesteren PJ, Kooistra T, Lansink M, van Kamp GJ, Asscheman H, Gooren LJ, et al. The effects of sex steroids on plasma levels of marker proteins of endothelial cell functioning. Thromb Haemost 1998;79:1029-33.

50. Newby DE, Wright RA, Labinjoh C, Ludlam CA, Fox KA, Boon NA, et al. Endothelial dysfunction, impaired endogenous fibrinolysis, and cigarette smoking: A mechanism for arterial thrombosis and myocardial infarction. Circulation 1999;99:1411-5. DOI: 10.1161/01.CIR99.11.1411.

51. Wannamethee SG, Lowe GD, Sharper AG, Rumley A, Lennon L, Whincup PH. Associations between cigarette smoking, pipe/cigar smoking, and smoking cessation, and haemostatic and inflammatory markers for cardiovascular disease. Eur Heart J 2005;26:1765-73. DOI: 10.1093/eurheartj/ehi183.

This work is available in Open Access model and licensed under a Creative Commons Attribution-NonCommercial 3.0 Poland License - http://creativecommons.org/ licenses/by-nc/3.0/pl/deed.en. 